\title{
Pseudo-quantities, new public management and human judgement
}

\section{Sven-Eric Liedman}

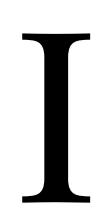

$\mathrm{n}$ this article I will introduce a new concept: pseudoquantities. A pseudo-quantity is a spurious quantity that purports to indicate the dimensions of something but is actually arbitrary and, if taken at face value, misleading. A real quantity informs us about the number, weight or velocity of something and is, in this respect, always more exact than even the most exhaustive verbal description. By contrast, a pseudo-quantity is less nuanced and less exact than a wellinformed and conscientious verbal evaluation.

The term pseudo-quantity is new, but the phenomenon is well known to researchers and has become the subject of a rapidly growing stream of literature. ${ }^{1}$ The new term would primarily be intended to provide insight into the on-going mechanisms and processes that underlie this phenomenon. Furthermore, this

\footnotetext{
${ }^{1}$ The literature that addresses the quantification of everything, especially concerning education and science, is overwhelmingly rich. See, e.g., Ball, 2004, Marglin, 2008, Slaughter and Rhoades, 2004 and Hasselberg, 2012
} 
term has a critical potential that is urgently needed at a time when many individuals erroneously believe that pseudoquantities can be used to gain both time and perspective.

In the first part of the article, I will present the new concept and its background in the concepts of quality and quantity. The importance of this term is pertinent to the founding of New Public Management (NPM) in the public sector. NPM will be treated in the following section. I will specifically highlight how this process influences education and research. In the conclusion, I summarise my argument and provide insight regarding a possible alternative.

\section{Qualities, quantities and pseudo-quantities}

The distinction between quality and quantity can be traced back to Aristotle. Quality provides an answer to the question "Of what sort?" (poiós, lat. qualis), and quantity answers the questions of "How many?" or "How much?" (posós, lat. quantis). According to Aristotle, quantity and quality represent two spheres of reality that could never meet. ${ }^{2}$ This opinion remained dominant among philosophers until the pinnacle of the scientific revolution in the $17^{\text {th }}$ and $I 8^{\text {th }}$ centuries, when an increasing array of qualitative standards could be successfully quantified. ${ }^{3}$ Even more important for the immediate experience

\footnotetext{
2 The background and history of the concepts of quality and quantity are presented succinctly and in relatively greater detail in Blasche et al., 1989 and Hager et al., 1989. Aristotle presents the concepts in several different writings, most comprehensively in Metaphysics, Book V, 13, 1020 a 7-11. See, e.g., Aristotle, 1933, pp. 256-61.

${ }^{3}$ Isaac Newton's Opticks, 1704, represented a real breakthrough, as Newton was able to quantitatively determine the colours in the spectrum as different refractions of light. Thus far, colours had been
} 
of the world, was the massive introduction of quantities in urbanised life since the late $15^{\text {th }}$ century. Double-entry bookkeeping was an important innovation, and the development of statistics that increasingly relied on numerical data also paved the way for a spontaneous conception of reality as fundamentally consisting of quantities. ${ }^{4}$

Modern life is imbued with quantities and quantifications. Real quantities provide a more accurate idea of reality than any verbal description. To state that New York City had 8, I 75, I33 inhabitants in 2010 is more exact than to describe how large and crowded the city is. The fact that the speed of light is $299,792,458 \mathrm{~m} / \mathrm{s}$ in a vacuum reflects the type of precise calculations that neither eloquence nor poetry can ever match.

These successful quantifications have prompted the idea that everything in reality can be quantified. Lord Kelvin, the great British physicist, previously remarked as follows: "When you cannot express it in numbers, your knowledge is of a meagre and unsatisfactory kind." A slightly revised version of this utterance still appears at the Social Science Research Building in Chicago. ${ }^{5}$ The following statement is a more recent example of the same idea: "If you cannot measure it, you cannot manage it. ${ }^{6}$ Here, we are close to the subject of this article. Quantification is an efficient tool that can be used by and for management.

viewed as proto-typical examples of real qualities that could never be expressed in quantitative terms (cf. Hall, 1993 and Berlinski, 2001).

${ }^{4}$ For the massive introduction of quantities in economic and social life, see Poovey, 1998.

${ }^{5}$ Quotations from Kuhn, 1961.

${ }^{6}$ Kaplan and Norton, 1996, pp. 21 
Of course, those who offer such sweeping statements regarding the overall importance of quantifying everything are fully aware that some values in life cannot be measured. It would be unreasonable to attempt to quantify the intensity of a love relationship. You may claim that Shakespeare (or Dante or another writer) is the greatest writer of all time, but people of normal intelligence know that one cannot quantify his greatness. Economic value can be quantified, but the value of friendship cannot.

To the best of my knowledge, this notion is uncontroversial. The conflict in the actual situation concerns quantification versus well-grounded human judgements concerning extremely complicated areas, such as schools, universities and health care. Pseudo-quantities are most controversial in these fields. The desire for all-inclusive quantification has given rise to a steadily increasing number of bad or spurious quantities, which I will call pseudo-quantities. A pseudo-quantity is a quality that can more accurately be characterised verbally (either by description or by more expressive means). ${ }^{7}$

However, it is important to distinguish between two types of pseudo-quantities: simple and composite. The latter type is the most important and the most harmful.

For an idea of simple pseudo-quantities, let us begin with an extremely simple example: a movie review. Movie reviews can be found in newspapers, in magazines and on the Internet. In such a review, a movie is presented, its plot is described and evaluations are given. However, in recent decades, films have

${ }^{7}$ In this definition, I am not taking a position on the controversy between adherents of quantitative versus qualitative methods in social science. For a discussion of this issue see, e.g., Neuman, 2011. 
also been given a specific mark or grade in the form of one to five stars or other simple symbols.

Such grades represent a typical (but relatively harmless) pseudoquantity. Ideally, such a review provides a full and rich evaluation of a movie. The grade represents an abbreviated form of the full review and may be useful to readers who are hurried; its popularity could then be attributed to the stresses of modern life. First, such grades facilitate quick comparisons with other movies. Second, the stars that have been attributed to the various on-screen movies may assist you in choosing a movie to view. ${ }^{8}$

The grade that is given to a movie is a pseudo-quantity because the quality is better defined by the full evaluation of the movie. The full review articulates the reasons that a particular viewer may view a film positively and why some interested cineaste specifically ought to view this film rather than another film that may be equally excellent.

A composite pseudo-quantity may consist of first-class statistical material. Let us examine one particular example to clarify this notion. In recent decades, university rankings have developed into a flourishing industry influencing students,

${ }^{8}$ For example, a classical movie, such as Stanley Kubrick's Dr. Strangelove, which is easily purchased or rented as a DVD, is given five stars by most reviewers. This grade means "excellent" or "worldclass", but the number does not provide insight into why and how the film is extraordinary. To find answers to these questions, one must consult the review of a well-known movie specialist. On the Internet, you can easily find several of these reviews. Here, I have chosen Christopher Null's review, which provides a much more qualified evaluation of this remarkable movie than the mere designation of five stars, Null, 2004. 
teachers, politicians and administrators. The two most well known international ranking systems are the Shanghai system ${ }^{9}$ and the British World Universities report, which is organised by the Times Higher Education Quarterly Supplement. The former system includes hard facts: first, the number of articles that a university staff has published; second, the number of citations in other scientific articles that these articles have received according to the Citations Indexes; and third, the number of Nobel Prizes and Field Medals (in mathematics) that have been awarded to faculty members of a university. However, why are these indicators considered valuable? More importantly, the manner in which one factor is evaluated in comparison with another factor is arbitrary. How many articles is a Nobel Prize worth? How many citations? ${ }^{10}$ The prima facie objectivity gives way to capriciousness.

The British World Universities Report bases its rankings on several different indicators but also assigns weight to subjective evaluations. Hence, the reputation of a university is important for its place in the resulting "league table". This ranking is a good example of a simple pseudo-quality and an extremely risky category. ${ }^{11}$ The riskiness seems unfortunate, as the league tables are intended to replace evaluations that are conducted by a committee of experts. According to the spokesmen for the

\footnotetext{
${ }^{9}$ The English name of this system is the Academic Ranking of World Universities (ARWU), which is organised by the Shanghai Jiao Tong University, ARWU, 2011.

${ }^{10}$ Furthermore, Field Medals and Nobel Prizes are few (even if the fake prize in economics is included), and it may be partly accidental for a university to receive such a prize.

${ }^{11}$ In the literature in the field, there is a famous example of this risk. Students who had to list the best law schools included Princeton, although Princeton does not have a law school. See: Frank and Cook, 1995
} 
new system, the reason for this intended change is that such committees may obtain results that are biased. This argument presupposes that well-grounded, versatile evaluations are less reliable than a mechanical summation of certain quantities and a pseudo-quantity that may result from a rapid assessment. On this basis, human judgement is replaced by seemingly exact, but arbitrary numbers.

The ranking of universities is a relatively new phenomenon. However, another type of pseudo-quantity is age-old and likely to survive all of us: school grades. However fine-grained the scheme of grades may be, a good teacher can always more aptly characterise a pupil in his or her own words than by issuing a grade. A grade may be a number, a letter or a short characteristic, such as laudatur, but it does not make specific claims regarding a pupil's study results. In short, school grading systems suffer from the same shortcomings as the number of stars that a movie receives.

However, I do not believe that we will ever have modern schools without grades. The reason is simple; we live in a society and a world in which anonymity reigns in most social relations and in which there are more competitors than positions in many careers. ${ }^{12}$ Grades constitute a simple method of distinguishing those who may be viewed as superior to others with respect to a certain educational level or position. However, such a process is risky: one cannot be certain that the person with the highest grades will be the best physician, lawyer, or economist. Those with the highest grades may be overly obedient and less original and creative than some of their classmates.

${ }^{12}$ Aas, 2006 
Pseudo-quantities can also indicate other valuable and interesting information. One school may give higher grades than another school, or children from one social stratum may be disfavoured in comparison with those from another stratum. Such results constitute important facts.

Each good quantity in a composite pseudo-quantity may also be of great interest. In this respect, the ranking of universities does not differ from the ranking of, for example, vacuum cleaners in Consumer Reports or Which? or, in Sweden, Råd \& Rön. As consumer reports can indicate how well various models can eliminate dust or pet hairs and how noisy such machines are, the number of citations may give you a specific idea of how influential an article is or has been. Furthermore, by studying a Quotation Index more closely, you may obtain good information regarding how new specialties in science are formed by studying how a group of scientists (often in different countries) begins to quote the articles of one another and exclude representatives of adjacent specialities. ${ }^{13}$

\section{New Public Management}

Concepts such as quality control, quality assurance and quality assessment have been extremely frequent topics of discussion in recent decades. Even the Japanese kaizen, which is normally translated as "improvement", has found a place in English and other Western languages. These notions were originally used in industrial production, ${ }^{14}$ but they are currently spreading to other fields, such as health care, education and research. In the public sphere, these concepts must be viewed as parts of new

\footnotetext{
${ }^{13}$ See, e.g. Hage and Meeud, 2006, and Ziman, 1987

${ }^{14}$ Juran, 1995
} 
public management $(\mathrm{NPM})^{15}$ that refers to the general policy intended to improve public efficiency through better management and the type of free competition that previously prevailed only in the private sphere. Recently, however, it has been posited that even more efficient methods of control which are typical of digital era governance against the threats of climate change, terrorism and new pandemics - are replacing NPM. ${ }^{16}$ Nevertheless, this possible shift has not influenced the central role of quality assessment and control.

NPM was created in response to the former bureaucratic model as described by Max Weber. This system was strictly hierarchical, and its responsibility was to implement the decisions of politicians. Administration was neutral and anonymous and was designed to obey all legitimate masters, irrespective of ideology. By contrast, NPM replaces administration with management. As Owen E. Hughes has remarked, the concept of management is wider than that of administration; the administrator is a servant, whereas the manager has a steering function. ${ }^{17}$

In the I970s and I980s, old bureaucracy was criticised for its inefficiency and ineffectiveness, and the state apparatus was

\footnotetext{
${ }^{15}$ The concept of new public management was coined by Christopher Hood (1991). However, the policy that this concept denotes was formed a decade earlier by politicians such as Margaret Thatcher and Ronald Reagan (cf. Hughes, 2003, pp. 2-4).

${ }^{16}$ Cf. Christensen and Lægreid, 2011, pp. 13. In a textbook, a third model is distinguished as "democratic governance". However, its contours appear to be blurred, and its influence is questionable. One of its characteristics, transparency, also appears to be typical of NPM, Pasquier and Villeneuve, 2012, pp. 4-11

${ }^{17}$ Hughes, 2003, pp. 6
} 
viewed as oversized. NPM should be the opposite (i.e., as resultoriented as the private sector).

Of course, NPM can be viewed as an ideology or, perhaps better, as a composite of different closely related ideological tenets. Neoliberalism must be mentioned because it forms the general intellectual (and emotional!) background of NPM. This concept is associated with such names as Milton Friedman, Gary S. Becker and other prominent members of the Chicago School of Economics. Politicians such as Margaret Thatcher, Ronald Reagan and their many supporters and successors throughout the world have formulated its main theses in a more praxis-oriented manner. International institutions, such as the International Monetary Fund (IMF), the World Bank Group (WBG) and the Organisation for Economic Co-operation and Development (OECD), were also important. The background was a period of stagflation (i.e., a combination of economic stagnation or even recession combined with inflation; this phenomenon is impossible according to the Keynesian doctrine that had dominated until then). However, equally important was an increasing conviction that the then-existing social welfare system hampered initiative and even diligence among ordinary people. All types of collectivism were banned, and the hard-working, endlessly creative entrepreneur was hailed as a paragon.

However, other currents of ideas that are less encompassing and more pragmatic than neo-liberalism also form NPM. First, managerialism must be mentioned. Central to managerialism is the idea that there is no substantial difference between the private and public sectors in that efficiency and effectiveness are equally important to both sectors. The work of a manager is instrumental in serving well-defined goals, but his or her 
freedom in choosing the optimal means of fulfilling his or her tasks must be encouraged. A good manager may use broad, unconventional methods to reach his ends. Humans are selforiented (if not openly selfish) creatures who are heavily influenced by different types of financial rewards. Managers are typical in this respect. homo oeconomicus reigns in managerialism as in neoliberalism. ${ }^{18}$

Even more specific economic trends, such as Transaction Cost Economics (TCE), whose fundamental assumptions pertain to man's fundamental economic rationality and selfishness, are mentioned as important. ${ }^{19}$ These trends do not change the overall view of the intellectual background of NPM.

However, it has been maintained that the shift from old-style bureaucracy to the new way of managing the public sector is greater in theory than in practice. ${ }^{20}$ To respond to this assertion, I will object that the real changes in many spheres have been radical and profound. In the school system and in universities, a completely new climate is currently dominant compared with the situation only decades ago.

\footnotetext{
${ }^{18}$ For a discussion of neoliberalism and managerialism and their importance to NPM, see Bostron, 2011, pp. 17-30. Bostron traces the roots of managerialism back to $\mathrm{F}$. W. Taylor and his scientific management. This seems exaggerated as Taylor's ideas are more typical for industrial production than for the work within state bureaucracies, the latter marked by rather well-defined rules and duties. (cf. Hughes, 2003, p. 1f and passim).

${ }^{19}$ Bostron, 2011, pp. 27

${ }^{20}$ Hughes, 2003. pp. 5
} 


\section{Critique of pseudo-quantities}

The enormous success of pseudo-quantities in a society in which NPM is dominant in the public sector indicates that human judgement is being disregarded and replaced with inexact numbers. To sharpen the critique of pseudo-quantities, I must remind the reader of some fundamental concepts in statistics. Categorical variables are of two types: nominal and ordinal. Nominal variables have no natural ordering, such as religious affiliations (e.g., Christian, Muslim, Buddhist) or modes of transportation (e.g., bus, subway, private car). In contrast, ordinal variables are ordered, but the distance between them is unknown. A conservative person is considered more to the right than a liberal person, but a socialist is to the left of both. However, it is nonsensical to seek to determine the exact distance among the three categories. Finally, some interval variables have numerical distances between any two values, such as blood pressure levels or annual income. ${ }^{21}$

Evidently, school grades are tuned in to interval variables as soon as different grades are given a distinct numerical value (i.e., when a laudatur is determined as being exactly three times as good as an approbatur or an $A$ as being a certain number of times better than an $C$ or an $E$ ). Of course, it is nonsensical to claim that a laudatur student knows exactly three times as much as his approbatur classmate. The values that are given to different grades constitute a type of tacit agreement regarding how grades should be handled (e.g., at applications of different types).

This system may appear to be unproblematic. Everyone is informed about the system, and teachers and students must

${ }^{21}$ Agresti, 2002, pp. 1 
adjust to it. A scrupulous teacher may still experience difficulties. He or she is significantly better informed about the students and their actual knowledge, their potential and their shortcomings than the grades could ever indicate. In addition to grades, teachers possess a wealth of information regarding their students.

It may be interesting to compare this problem with the investigations of the spontaneous attitudes of the general public that are conducted by opinion institutes, firms specialising in market research studies and other entities. Here, most people who answer such questions are not more informed than they can express with their simple answers. If some person who is unknown to me inquires about my political sympathies, my ideas regarding public transportation in my home city, or my opinion of some trademark, then my response is sufficient to form a minor but substantial part of a trustworthy investigation of what people generally think about politics, public transportation, or a certain trademark.

Of course, all nuances are lost in such investigations. Expert answers are not worth more than those of ignorant people. A professional assessment of a certain phenomenon is not pursued; rather, general public opinion is sought.

Evidently, if I am asked to give a number between I and Io as an answer to the question of how much I trust the public transportation system in my home city, then my answer must form a pseudo-quantity. However, to the investigators, my arbitrary answer poses no problem because I am only one of some roo० people who were asked the same question. A city that has ordered such an investigation obtains an idea of the degree of satisfaction of the average citizen with respect to the 
transportation system. The opinion of experts is not sought; rather, such investigations seek to obtain information regarding general attitudes.

The pseudo-quantities that currently play such a crucial role in parts of the public sector differ from the outcomes of public polls. Here, it is the experts (i.e., the professionals), who must formulate pseudo-quantities concerning central parts of their field of expertise. In other cases, their own work is assessed with the assistance of pseudo-quantities. The tyranny of arbitrary evaluations can be observed everywhere: in health care, in police service, in the school system, in universities and in other arenas. In various fields, complicated professional judgements are now expressed in terms of pseudo-quantities.

What is the reason for this rapidly increasing need for numbers whose collection and analysis involve an increasing number of jobs for both professionals and public managers? Several arguments are given, such as transparency, economic efficiency, and objectivity in the sense of impartiality. These arguments are the standard arguments that are given for NPM in general, and pseudo-quantities are a natural part of NPM. More adequately expressed, the ambition of those who support NPM is to render social reality quantifiable. In this effort, these individuals support Lord Kelvin's conviction that real knowledge must be expressed in numbers. However, Lord Kelvin had no conception of such unreliable numbers as pseudo-quantities.

The pseudo-quantities that are typical in NPM are unrelated to intellectual standards but more pertinent to social ideals, values and power. Pseudo-quantities primarily flourish in the increasing amount of documents that professionals must complete. Of course, these documents contain much more 
information than merely numbers, but numbers play a substantial part as the most easily comparable element of all of the information in these documents.

Thus, numbers meet one of the main values in NPM, namely transparency. Every part of the public sector must be transparent to outside parties (and to the powers above). This transparency can serve as (and sometimes actually is) a democratic value: when a man or woman in the street obtains access to information that is important to him or her as an individual, a professional or a member of a democratic society. However, this transparency is frequently also a managerial interest and, indirectly, a political interest. A public manager, whose real influence is more substantial than that of an oldfashioned administrator, is eager to monitor and control what is occurring in the public sector and especially to verify that the quality of its activities meets standards. This quality is expressed in quantitative terms, primarily in pseudo-quantities.

Most politicians who are unconscious adherents of the ideals of NPM also utilise such results and often refer to them. Thus, pseudo-quantities have a role in the process of deprofessionalisation. ${ }^{22} \mathrm{~A}$ professional is a person who has received specialised education in his or her field of expertise and is therefore relatively free to make decisions concerning matters

22 The literature on professions, semi-professions, and professionalisation and, more recently, on de-professionalisation is abundant. The standard reference here is that of Andrew Abbott, 1988. Also important is Abbott, 2001. See also Freidon, 2001 and, concerning the Nordic countries, Aili et al., 2007. The unclear professional status of the librarian is treated in Freeman, 1997, and the counterpart treatment of the teacher can be found in Gore and Morrison, 2011 and Hyland, 1986. An article that is critical of the deprofessionalisation thesis is that of Clark, 2005. 
that exclusively belong to the same field of expertise. A teacher is the only person who knows how to teach his or her own students and evaluate their learning performance. Of course, experience, cooperation with colleagues and other factors are always important, but in his or her own field, a teacher is always more trustworthy than outsiders, such as politicians, journalists, or even the students themselves and their parents. The outsiders (in the former instance, the democratic institutions) must make decisions concerning all external circumstances, from the school curricula to economic factors. Nevertheless, the professional still has a unique field of competence.

It has been questioned whether a primary or secondary school teacher, a nurse or librarian has ever had a real professional status. The concept of a semi-profession has sometimes been used to denote those categories that have not attained the real professional autonomy of a doctor or a lawyer. ${ }^{23}$

Irrespective of these questions, in an NPM setting, the professional status of librarians, nurses and teachers has deteriorated, and even the medical profession is threatened. Different mechanical systems of assessment have been designed to evaluate and thus steer one's work as a doctor. ${ }^{24}$

In this process of de-professionalisation, the abundance of pseudo-quantities must be observed. The activities of different types of professionals in public service must be directly supervised and controlled by public managers and indirectly by politicians because it is necessary both to verify that the various tasks are duly fulfilled and to monitor how these tasks are

\footnotetext{
${ }^{23}$ Concerning the professional status of the nurse, see Parkin, 1995.

${ }^{24}$ For a discussion of this issue, see Heath 2008.
} 
completed. Through some cleverly elaborated schemes of measurement, all professional activity will be visible from the outside. At a minimum, this notion is the guiding principle. Through pseudo-quantities, the quality of all public activity will be transparent and will be possible to rank in terms of the service of public managers, politicians, and the general public. Given the untrustworthiness of pseudo-quantities, this endeavour is evidently futile.

\section{Concluding remarks}

Pseudo-quantities are not an invention of recent decades. However, they proliferate in an age in which all types of quality assessments are expected to be expressed in quantitative terms and in which impartiality and illusory exactitude appear to be more reliable than qualified expert judgement.

In the public sector, the flourishing of pseudo-quantities is intimately related to new public management, whose main ideal is to ensure that the public sector is as effective and efficient as a private enterprise. A system of controls is instituted to verify that the highest possible efficiency is achieved. Here, schools, hospitals, courts and other institutions are measured against standards that are as mechanical as those used, for instance, in a car plant. Everything in the public sector must be transparent to outsiders, including politicians, managers, and the general public. This transparency requires a substantial deprofessionali-sation of professional work and also leads to a loss of status and prestige among professions. Yet, it is also likely to increase the risk that teachers, doctors, scientists and other professionals would concentrate more on fulfilling assessment goals, rather than completing the most important tasks that belong to their professions. 
However, the real inadequacy of all assessments that are expressed in pseudo-quantities is equally important. Qualified judgements that are marked by expertise are always more reliable, even if they require more time and more money than an assessment that is based on pseudo-quantities.

Of course, in the last instance, an expert's assessment may be summarised in a simple quantity, similar to the manner in which a teacher's assessment of a pupil is currently summarised in the form of a grade. In this case, pseudo-quantities may be viewed as a type of shorthand that can never replace a more complete assessment, as in the case of the star or point systems that are used in film reviews.

Needless to say, all public work must be supervised and assessed in the interest of all citizens in their capacity as taxpayers, students, parents, caretakers, etc. However, it is specifically this interest that increases the importance of exposing the illusory precision of pseudo-quantities.

Similarly, higher education and research must be evaluated by real judgements that are marked by expertise, rather than by some mechanical use of numbers of articles, citations, or awards, that do not pertain to creativity, originality or even real scholarship.

\section{References}

Aas, Gro Hanne. Likhet utan solidaritet? Idéhistoriske studier av karakterer $i$ utdanning og meritokrati. With an English summary: Equality Without Solidarity? Studies from the Vantage Point of History of Ideas on Uses of Marking 
Systems in Education and of Meritocracy. Göteborg, Arachne, Institutionen för idé- och lärdomshistoria, 2006.

Abbott, Andrew. The System of Professions: An Essay on the Division of Expert Labour. Chicago, University of Chicago Press, 1988.

Abbott, Andrew. "Professions, sociology of." In International Encyclopedia of the Social \& Behavioral Sciences, Vol. I8, Amsterdam, Elsevier, 200I.

Agresti, Alan. Categorical Data Analysis. Gainesville, Florida, Wiley-Interscience, 2002 [I993].

Aili, Carola, Lars-Erik Nilsson et. al. (eds.). In Tension Between Organization and Profession: Professionals in Nordic Public Service. Lund, Nordic Academic Press, 2007.

Aristotle. Metaphysics. Greek and English, transl. by Hugh Tredennick, Loeb Classical Library. Cambridge, MA and London, Harvard Univ. Press, I933.

ARWU. "Academic Ranking of World Universities". http://www.shanghairanking.com/. [Retrieved 27 May 2OI 2].

Ball, Stephen J. Education for Sale! The Commodification of Everything. King's Annual Education Lecture 2004. http://sys.glotta.ntua.gr/Dialogos/Politics/[Retrieved 20 May 2OI2].

Berlinski, David. Newton's gift: How Sir Isaac Newton Unlocked the System of the World. London, Duckworth, $200 \mathrm{I}$.

Blasche, S., Urban, W et al. "Qualität." In Historisches Wörterbuch der Philosophie, Vol. 7, Joachim Ritter and Karlfried Grunder (eds.), pp. I747-I780. Darmstadt, Wissenschaftl. Buchgesellschaft, I989. 
Bostron, Jonathan. "Basic NPM Ideas and Their Development." In The Ashgate Research Companion to New Public Management, Tom Christensen and Peter Lægreid (eds.), pp. I7-30. Farnham, Ashgate, 20 I I.

Christensen, Tom and Lægreid, Peter (eds.), The Ashgate Research Companion to New Public Mangement, Farnham, Ashgate, 20II.

Clark, Chris. "The Deprofessionalisation Thesis, Accountability and Professional Character." Social Work \& Society International Online Journal, Vol. 3, no. 2, 2005, pp. I82I90.

Frank, Robert and Cook, Philip J. The Winner-Takes-AllSociety: How More and More Americans Compete for Ever Fewer Fewer and Bigger Prizes, Encouraging Economic Waste, Income Inequality, and Impoverished Cultural Life. New York, The Free Press, I995.

Freeman, Mike. "Is librarianship in the UK a true profession, a semi-profession or a mere occupation?" New Library World, Vol. 98, no. 2, I997, pp. 65-69.

Freidon, Eliot. Professionalism: The Third Logic. Cambridge, Polity Press, 200I.

Gore, Jennifer M. and Morrison, Kellie. "The perspectives of a (semi)profession: Challenges in the governance of teacher education." Teacher and Teacher Education, Vol. I7, no. 5, 20 I I, pp. 567-582.

Hage, Gerald and Meeud, Marius. (eds.) Innovation, Science, and Institutional Change, New York, Oxford University Press, 2006.

Hager, F.P., Urban, W. et al. "Quantität.” In Historisches Wörterbuch der Philosophie. Vol. 7, Joachim Ritter and Karlfried Grunder (eds.), pp. I792-I828. Darmstadt, Wissenschaftl. Buchgesellschaft, I989. 
Hall, A. Rupert. And All Was Light: An Introduction to Newton's Opticks. Oxford, Clarendon, I993.

Hasselberg, Ylva. "Demand or discretion? The market model applied to science and its core values and institutions." Ethics in Science and Environmental Politics, Vol. I2, 20I2, pp. 35-5 I.

Heath, Iona. Matters on Life and Death: Key Writings. Abingdon: Oxfordshire, Radcliffe Publishing, 2008.

Hood, Christopher. "A public management for all seasons." Public Administration, Vol. 69, no. I, I991, pp. 3-19.

Hughes, Owen E. Public Management and Administration. New York, Pelgrave, 2003 [1994].

Hyland, Terry. "Professionalism, ethics and work-based learning." British Journal of Educational Studies, Vol. 44, no. 2, I986, pp. I68-80.

Juran, Joseph M. A History of Managing for Quality: The Evolution, Trends, and Future Directions of Managing for Quality. Milwaukee, WIS, ASQS Quality Press, I995.

Kaplan, Robert S. and Norton, David P. The Balanced Scorecard: Translation Strategy into Action. Boston, Harvard Business School, I996.

Kuhn, Thomas S. "The function of measurement in modern physical science." In Quantification: A History of the Meaning of Measurement in the Natural and Social Science, Harry Woolf (ed.), Indianapolis \& New York, BobbsMerrill, I96I.

Marglin, Stephen A. The Dismal Science: How Thinking Like an Economist Undermines Community. Cambridge, MA, Harvard University Press, 2008.

Neuman, William Lawrence. Social Science Methods: Quantitative and Qualitative Approaches. Boston, MA, Allyn \& Bacon, 20I I. 
Newton, Isaac. Opticks, or a Treatise of the Reflections, Refractions, Inflections \& Colours of Light. New York, Dover Publ., repr 1952 [1704].

Null, Christopher. "Dr. Strangelove, or: How I Learned to Stop Worrying and Love the Bomb." 2004.

http://www.filmcritic.com/misc/emporium.nsf/reviews/Dr.Strangelove-or-How-I-Learned-to-Stop-Worrying-and-Lovethe-Bomb [Retrieved 27 May 2012].

Parkin, Paul A.C. "Nursing the future: An examination of the professionalization thesis in the light of some recent developments." Journal of Advanced Nursing, Vol 21, no. 3, I995, pp. 56I-67.

Pasquier, Martial and Villeneuve, Jean-Patrick. Marketing Management and Communications in the Public Sector. London \& New York, Routledge, $20 \mathrm{I} 2$.

Poovey, Mary. A History of the Modern Fact: Problems of Knowledge in the Sciences of Wealth and Society. Chicago and London, The University of Chicago Press, I998.

Slaughter, Sheila and Rhoades, G. Academic Capitalism and the New Economy: Markets, State and Higher Education. Baltimore, MD, The Johns Hopkins University Press, 2004. Ziman, John M. Knowing Everything about Nothing: Specialization and Change in Science Careers. Cambridge, Cambridge University Press, 1987.

Sven-Eric Liedman is Professor Emeritus in History of ideas and science at University of Gothenburg, Sweden. 